\title{
Estados emocionais de enfermeiros no desempenho profissional em unidades críticas*
}

\author{
THE NURSES' EMOTIONAL PARAMETERS ON THE PROFISSIONAL PERFORMANCE \\ AT INTENSIVE CARE UNITS
}

\section{ESTADOS EMOCIONALES DE ENFERMEROS EN EL DESEMPEÑO PROFESIONAL EN UNIDADES CRÍTICAS}

\section{Milva Maria Figueiredo De Martino', Maira Deguer Misko²}

\section{RESUMO}

O objetivo desta pesquisa foi analisar as variáveis psicológicas de enfermeiros, obtidas por meio da Lista de Estados Emocionais LEP - cujo questionário foi respondido no início e no término do plantão. Fizeram parte da pesquisa $(n=70)$ enfermeiros, que trabalhavam no Hospital das Clínicas / UNICAMP sob o regime de $6 e$ 12 horas diárias, em atividades desenvolvidas no Centro Cirúrgico (CC), Unidade de Terapia Intensiva (UTI), Unidade Coronariana (UCO) e Pronto Socorro (PS), com idade média de 33,88 anos. Os resultados permitiram constatar que o perfil emocional dos enfermeiros sofre alterações no decorrer do plantão, o que pode ser creditado ao desgaste e ao estresse próprios da atividade de prestar assistência, sobretudo nas unidades, onde há exigência de alto nivel de habilidades e necessidade de respostas imediatas em emergências. $O$ cansaço foi uma variável de intensidade forte, no final do plantão em todas as unidades.

\section{PALAVRAS-CHAVE}

Estados emocionais.

Enfermeiras.

Trabalho em turnos.

Unidades de terapia intensiva.

\begin{abstract}
The aim of this study was to analyze the nurses' psychological variables taken from Engelmann's List of Emotional States and based on the questionnaire answered by the subjects at the beginning and end of each shift in differentunits of Hospital das Clinicas, UNICAMP on the six-hour and twelve-hour schedules in activities developed at the surgical center (SC), Intensive Care Unit (ICU), Coronary Unit (CU) and Emergency Room (ER) with the average age of 33.88 years old. The results allowed us to certify the nurses' emotional parameters have alterations during the shift, which can be related to the burnout and stress of the care delivery activity, even more in units where it demands immediate answer skill and need on emergency. Tiredness was a strong variable at the end of the shifts in all units. The results obtained at the beginning and end of the shifts were statistically compared using the Kruskal-Wallis method and the group profiles demonstrated a variety offeelings and intensities that were statistically significant $(p=£ 0.05)$.
\end{abstract}

\section{KEYWORDS}

Emotional states.

Nurses.

Shift work.

Intensive care units.

\section{RESUMEN}

Oobjetivo de esta investigación fue analizar las variables psicológicas de enfermeros, obtenidas por medio de la Lista de Estados Emocionales LEP cuyo cuestionario fue respondido al inicio y fin del turno. Hicieron parte de la investigación ( $n=70)$ enfermeros, que trabajaban en el Hospital de las Clínicas / UNICAMP bajo el régimen de 6 y 12 horas, en actividades desarrolladas en el Centro Quirúrgico (CC), Unidad de Cuidados Intensivos (UCI), Unidad Coronaria (UCO) y Pronto Socorro (PS), con edad media de 33,88 años. Los resultados permitieron constatar que el perfil emocional de los enfermeros sufre alteraciones en el transcurso del turno, lo que puede deberse al desgaste y al estrés propios de la actividad de prestar asistencia, sobre todo en las unidades, donde hay exigencia de alto nivel de habilidades y necesidad de respuestas inmediatas en emergencias. El cansancio fue una variable de intensidad fuerte, al final del turno en todas las unidades.

\section{PALABRAS CLAVE}

Estados emocionales.

Trabajo por turnos.

Enfermeras.

Unidades de Cuidado intensivo.
* Projeto Financiado pela FAPESP. N.98/01297-5

1 Professor Associado do Departamento de Enfermagem da Faculdade de Ciências Médicas UNICAMP.

Orientadora do projeto. milva@obelix.unicamp.br

2 Bolsista de iniciação científica FAPESP. Aluna do curso de graduação em enfermagem da FCMUNICAMP(1998). mairadm@bol.com.br 
Milva Maria F. De Martino Maira Deguer Misko

\section{INTRODUÇÃO}

Foram desenvolvidos no campo da psicologia experimental, estudos empregando medidas de estados subjetivos com resultados mais completos e precisos ${ }^{(1-2)}$. O termo "estado subjetivo" engloba os fenômenos de emoções, sentimentos, estados de ânimos, paixões, afetos ou estados afetivos, que a literatura da psicologia não conseguiu diferenciar um dos outros ${ }^{(3)}$.

Fez-se um levantamento empírico exaustivo de 370 palavras do dicionário português, usadas para descrever diferentes estados subjectivos, sentimentos, paixão, humor e afeição, a fim de não introduzir hipóteses a priori a respeito de estados subjetivos mais importantes ou situações mais significativas ${ }^{(1-2)}$. Resultou, deste trabalho, um instrumento de investigação, Lista de Estados Emocionais Presentes (LEP), que foi utilizado como material básico para a realização desta pesquisa.

$\mathrm{O}$ aspecto emocional pode vir a interferir no cotidiano das pessoas, prejudicando-as dependendo do estágio, como no caso do estresse e, muitas vezes, tornando-as alheias a seus próprios sentimentos ${ }^{(4)}$.

$\mathrm{Na}$ enfermagem, vive-se uma realidade de trabalho cansativo e com muito desgaste devido à convivência com a dor e sofrimento dos clientes. Se o indivíduo não souber equilibrar bem essa situação utilizando-se de mecanismos de transferência, pode acometer um estado de ansiedade; que quando excede o nível mínimo leva a diminuição da capacidade de tomar decisões, incorrendo em erros adicionais, gerando assim um circulo vicioso, e a conseqüentes níveis progressivos de estresse $^{(5-6)}$.

A diversidade de atividades executadas, as interrupções freqüentes, os imprevistos, $o$ contato direto com o sofrimento e morte são fatores agravantes no trabalho de enfermagem que, na maioria das vezes, podem conduzir ao desgaste mental ${ }^{(6)}$.

A crise existencial no trabalho de enfermagem que faz com que seus profissionais experimentem insatisfação, ansiedade, desestímulo e acomodação por não visualizarem, no futuro, uma perspectiva de avanço que pode interferir no estado psicológico do sujeito ${ }^{(7)}$.
O desajustamento nos horários habituais dos membros da equipe de enfermagem é uma questão que necessita hoje de maiores investigações, pois sabemos da existência do relógio biológico e os mecanismos que podem alterá-los, um deles o trabalho em turno e principalmente, quanto aos locais, unidades de tratamentos críticos, tendo como conseqüência alterações no estado emocional ${ }^{(8-10)}$.

Vários estudos têm demonstrado que a existência de fatores externos e internos nos indivíduos, acometidos pelo trabalho em turno pode causar transtornos que geram o estresse, considerado como uma fase mais avançada das alterações emocionais ${ }^{(4,6,8)}$.

Estudos comprovaram que para os enfermeiros de unidades de terapia intensiva (UTI), o local é muito tenso, e que isso poderia interferir no seu estado emocional, levando ao desgaste geral do organismo e, conseqüentemente, provocando estresse ${ }^{(6)}$. Observou-se que $(59,4 \%)$ dos profissionais encontravam-se estressados, resultados confirmados estatisticamente através da prova não paramétrica de "U" de MannWhitney. No entanto, quanto ao tempo de trabalho na UTI pode-se perceber que as pessoas com o tempo de trabalho abaixo dos cinco anos e acima de dez anos parecem sofrer mais as influências do estresse no trabalho. Os enfermeiros, nas instituições hospitalares, estão expostos a situações de elevada tensão emocional, associadas às longas jornadas de trabalho, condições de insalubridade do ambiente laboral, baixos salários e o duplo emprego, fatores que aumentam também a possibilidade do absenteísmo.

Outra pesquisa com enfermeiras de clínicas médica e cirúrgica de um hospital de ensino, com o objetivo de analisar aspectos psicológicos ligados às variações do ritmo circadiano de sinais fisiológicos, utilizando a LEP, demonstrou como resultados: primeiramente dessincronização dos ritmos biológicos (temperatura oral), em conseqüência do esquema de turno; por outro lado, estados emocionais mais permanentes nas enfermeiras, independente dos turnos; efeitos do plantão, com locuções sobre estados emocionais, aparecendo ou deixando de se apresentar com intensidade forte no final do plantão e a quase ausência de estados emocionais negativos ("sentir-se culpado", "ter pena de 
alguém", "sentir ciúme de alguém", "sentir estranho", "faço pouco caso de alguém"). Entretanto, verificou-se a presença de locuções de afetos positivos correspondentes a locuções de alegria, alívio, calma, esperança, interesse, cuidado, reflexão, nas diversas condições, tanto no início como no final da série de plantões ${ }^{(8)}$.

Atualmente têm sido desenvolvidas pesquisas sobre estresse em enfermeiros e para, o enfermeiro que trabalha em hospital, vive no cotidiano várias causas que podem ser identificadas como fatores para o estresse $^{(4,11-12)}$.

Uma das fontes de estresse para a enfermeira é justamente o desequilíbrio emocional da equipe, conseqüência de múltiplos fatores, aos quais todos estão submetidos por atuarem em unidades de terapia intensiva ${ }^{(13-14)}$.

Diante do exposto, essa pesquisa procurou analisar o estado emocional presente nos enfermeiros durante o desempenho profissional, nas unidades de tratamento a pacientes críticos, considerados extremamente estressantes, nos diferentes turnos de trabalho, utilizando-se da LEP.

\section{MATERIAL E MÉTODO}

\section{Sujeitos}

Fizeram parte da pesquisa $(\mathrm{n}=70)$ enfermeiros que trabalhavam no Hospital das Clínicas/ UNICAMP sob o regime de 6 horas diárias (plantões matutino e vespertino) e 12 horas (plantão noturno), em atividades desenvolvidas no Centro Cirúrgico (CC), Unidade de Terapia Intensiva (UTI), Unidade Coronariana (UCO) e Pronto Socorro (PS). A faixa etária desta população foi de 23 a 50 anos, apresentando uma média de idade de 33,88 anos.

\section{Material}

Foram utilizados formulários com a Lista de Estados Emocionais Presentes-LEP ${ }^{(3)}$. A LEP corresponde a uma lista de 40 locuções, escritas em língua portuguesa, que traduzem estados de ânimos possíveis de se manifestarem. Estas locuções são escritas na primeira pessoa do singular, de forma a facilitar a avaliação do próprio sujeito que as lê, com o objetivo de assinalar o grau de intensidade sentido de um determinado estado, num determinado momento. Ao lado de cada locução encontra-se uma escala de quatro pontos, que representam os seguintes graus de intensidade : Forte, Mais ou menos Forte, Fraco e Nada, respectivamente numerados de 3, 2, 1 e 0 . A LEP assemelha-se à lista de Nowlis ${ }^{(15)}$. Sobre o questionário utilizado, a LEP é constituída de duas folhas. Na folha inicial achavam-se as instruções de como os sujeitos deverão preenchê-la e, na folha seguinte, as 40 locuções distribuídas ao acaso. Após cada uma delas encontra-se uma escala de intensidade. Este último ponto utilizado quando o sujeito quer relatar que determinado estado de ânimo não correspondia ao seu estado no momento em que preenchia a lista.

\section{Procedimentos}

A coleta de dados ocorreu durante o período de 10 de novembro a 15 de fevereiro de 1998. Todos os questionários foram aplicados no mesmo horário e nas mesmas condições (início e final do período de trabalho), tendo sido aplicados individualmente, logo após o enfermeiro ter recebido o relato verbal das ocorrências do período anterior. Primeiro era explicado o objetivo do trabalho e, após, solicitada a colaboração. Nenhuma explicação foi dada sobre as respostas, com a finalidade de evitar influência sobre os resultados.

Quando essas condições não conseguiam ser respeitadas por algum problema ocorrido no setor, cancelava-se o preenchimento do questionário e, em outro dia, aleatoriamente, voltava-se a campo para nova coleta.

A leitura das instruções e o preenchimento da LEP duraram de 3 a 5 minutos, excedendo um pouco o tempo inicialmente previsto. A lista de locuções foi apresentada aos sujeitos sob várias formas, sendo diferenciada pela ordem seqüencial aleatória em que apareciam as locuções.

\section{Aspectos Éticos}

Antes de se dar início a coleta de dados, foi encaminhada uma cópia deste projeto à Comissão de Ética do HC-UNICAMP e outra à Comissão de Ética e Pesquisa da Faculdade de Ciências Médicas - UNICAMP, que foram aprovadas.

Todos os profissionais que fizeram parte da amostra assinaram um termo de consentimento de sua participação, com base na resolução 196/96 e 251/97 do Conselho Nacional de Saúde referente aos aspectos éticos recomendados na realização de pesquisa em seres humanos.
Estados emocionais de enfermeiros no desempenho profissional em unidades críticas 
Milva Maria F. De Martino Maira Deguer Misko

\section{Tratamento de Dados}

Para análise estatística deste estudo, utilizou-se para a comparação de variáveis contínuas entre os três grupos, o teste de Kruskal - Wallis (não-paramétrico) e o teste exato de Fisher, aplicado na comparação de proporções e associação de variáveis.

\section{RESULTADOS E DISCUSSÕES}

Com base nos dados obtidos, teve-se um grupo relativamente jovem atuando nessas áreas, fato que pode ser explicado pelas características próprias das unidades, que exigem elevado grau de agilidade, destreza física e energia, 0 que é mais comum em pessoas jovens.

Resultados similares foram verificados em uma população de enfermeiros de $\mathrm{UTI}^{(6)}$, encontrando-se $40,6 \%$ na faixa etária de 20 a 30 anos e $46,9 \%$ entre 30 e 40 anos.

Como era esperado nesses dados, constatou-se que a maioria dos participantes era do sexo feminino, totalizando 67 mulheres ou $95,71 \%$, e apenas $3(4,29 \%)$ do sexo masculino. Conforme a característica gênero, não se encontrou, no $\mathrm{CC}$, nenhum enfermeiro, sendo a amostra $100 \%$ feminina no período de coleta de dados. No PS, observou-se 92,31\% dos participantes do sexo feminino e 7,69\% do sexo masculino, o que foi semelhante na UTI, onde $96,88 \%$ eram do sexo feminino e apenas $3,13 \%$ do sexo masculino.

A motivação para a escolha da enfermagem, que é constituída na sua maioria por mulheres, poderia estar condicionada a aspectos culturais, que prescrevem as atividades de cuidar como responsabilidade feminina, interligadas desde cedo na vida ${ }^{(13)}$.

É sabido que a enfermagem é uma profissão basicamente feminina, nãoénem mais nem menos do que a profissionalização da capacidade humana de cuidar, através da aquisição e aplicação de conhecimentos, atitudes e habilidades apropriadas dos papéis presentes na enfermagem.

O motivo de ser constituída essencialmente por mulheres é que a enfermagem traz em sua trajetória o cuidado, que estava delegado às mulheres, assumindo, desse modo uma carga grande de preconceito para as pessoas do sexo masculino que optam por essa área ${ }^{(6)}$.

Verificou-se que o percentual de $44,3 \%$ pertencia a enfermeiras do plantão noturno, quan- do as enfermeiras realizavam plantões em turnos de 12 por 60 horas, ou seja, trabalham 12 horas seguidas e folgavam 60 horas. Isto requer três equipes noturnas no hospital, elevando o número desses profissionais.

Vale ressaltar que, no HC / Unicamp, a dinâmica do trabalho em turnos ocorre de maneira fixa, o que pode ser um fator positivo, já que o trabalho em turnos alternantes leva a um estado de desgaste, por alterar os ritmos biológicos, conduzindo à dificuldade e lentidão de ressincronização desses ritmos ${ }^{(14)}$.

Os resultados alcançados, no presente estudo, puderam constatar, em relação aos profissionais da UTI, que há uma série de locuções subjetivas que apareceram tanto ao início como ao final do plantão com a mesma intensidade, ou seja, permaneceram estáveis.

Sentimentos de "medo", "susto", "fazer pouco caso de alguém", "estar devendo cuidado", "estar com nojo", "sentir-se culpado", "inveja", "estar com vergonha", "estar surpreso", "estar com pena", "raiva", "estar sem graça", "sentir-se humilhado" ou "triste"são referidos como ausentes na grande maioria das respostas, tanto ao início como ao final do plantão.

O que permaneceu estável porém, com intensidade forte, foram as locuções: "sinto saudade de alguém", "sinto uma necessidade", "sinto uma obrigação", "sinto um desejo", "estou com esperança" e "estou gostando de alguém".

Obteve-se, também, locuções que apareceram apenas ao início e ao final do plantão indicando efeitos específicos do plantão, as quais foram: "sinto-me interessado", "sinto-me calmo", "estou refletindo", sendo estas mais evidentes no início do plantão, já que após a jornada de trabalho, supõe-se que os profissionais não consigam manter o mesmo nível de reflexão e interesse justificado pelo desgaste. No final do plantão, as locuções "estou cheio", "sinto um alívio" apareceram com intensidade forte. $\mathrm{O}$ "estar cheio" provavelmente é conseqüência do cansaço e da tensão presentes durante o turno de trabalho.

O estar fortemente cansado, apareceu em $43,8 \%$ dos profissionais ao término do plantão, porém essa variável esteve presente, com igual intensidade, em $15,6 \%$ das respostas, o que leva a crer que muitos dos enfermeiros desta unidade chegam cansados, provavelmente por terem uma jornada dupla de trabalho. 
Um fato verificado quanto à locução "sentir-se orgulhoso" foi ela não ter sido um sentimento que apareceu significativamente nem no início nem no término do trabalho, ficando na maioria das respostas com intensidade variando entre "mais ou menos" e "fraco" principalmente nos grupos da UTI e do CC. Já para os enfermeiros do PS, este sentimento foi de intensidade forte em $42,3 \%$ dos sujeitos no início do plantão. No final caiu para $26,9 \%$, mas, em relação às outras unidades, manteve-se elevado, o que talvez justifica-se pela característica da importância da assistência de enfermagem prestada ao paciente que se encontra em situação crítica no momento.

Em relação aos grupos de CC e PS, algumas locuções também permaneceram sem alterações significativas entre o início e final do plantão, as quais predominaram com intensidade "nada", ou seja, as que os profissionais assinalaram não estarem sentindo. Dentre estas citou-se: "acho algo gozado", "estou com medo", "estou com sede", "acabo de levar um susto", "faço pouco caso de alguém", "sinto ciúme de alguém", "sinto atração sexual por alguém", "estou com nojo", "sintome culpado", "sinto inveja de alguém", "estou com vergonha", "tenho pena de alguém", "sinto raiva", "estou sem graça" e "sinto-me humilhado".

No grupo dos sujeitos do PS, 38,5\% dos enfermeiros referiram "não estarem conformados" no término do plantão, supõe-se que, pela rotina da unidade de rotatividade de pacientes e médicos, os enfermeiros sintam-se incomodados com algumas resoluções referentes à assistência ao paciente e à organização da unidade.

O que predominou fortemente ao início do plantão, no grupo do PS, foi que $53,8 \%$ dos enfermeiros mencionaram "interesse" e, também, $53,8 \%$ assinalaram "estarem calmos", proporções que, no término do plantão, foram de $19,2 \% \mathrm{e}$ $26,9 \%$, respectivamente, o que já era esperado após o plantão em uma unidade que exige do profissional agilidade e atenção o tempo todo no término do plantão $34,6 \%$ mencionaram "estarem fortemente cansados". Para esse item esperava -se uma percentagem maior devido às características de atendimento em uma unidade de PS.

No grupo do $\mathrm{CC}$, o sono apareceu com intensidade "forte" em 63,6\% dos enfermeiros ao final do plantão, sobretudo quando pensamos no plantão noturno e quando se relacio- na que há enfermeiros que têm jornada dupla de trabalho. Outros sentimentos que, ao final, foram assinalados com intensidade forte : $\mathrm{o}$ "sentir admiração por alguém", o "estar cheio", o "estar cansado" e o "sentir um alívio", todas características esperadas para o final de plantão.

Todas essas características estão firmemente relacionadas às unidades estudadas e com esta pesquisa procurou-se comparar os dados encontrados entre as unidades, os quais se seguem.

Com relação aos estados emocionais presentes, as enfermeiras das três unidades apresentaram características em comum pelo fato de que, na maioria das respostas, encontraram-se "sem intensidade" ou "fracas", sobretudo os sentimentos relacionados a "achar algo gozado", "medo", "susto", "fazer pouco caso de alguém", "nojo", "sentir-se culpado", "sentir inveja de alguém", "estar com vergonha", "sentir pena" e "raiva", "sentir-se humilhado".

A locução "sinto saudade de alguém", foi a mais freqüente no grupo do PS, com $53,85 \%$ de respostas com intensidade "forte" e com nenhuma resposta assinalada na intensidade "nada", ou seja, o sentimento foi de intensidade média nos profissionais desta unidade, enquanto que nas demais unidades predominou sentimentos com intensidades menores ou nenhuma.

A locução "estou sem graça", mostrou que houve diferença significativa (KruskallWallis $p=£ 0,005)$ comparando os grupos das unidades CC, PS e UTI. Em relação à intensidade "nada", obteve-se, para o grupo do PS, diferença significativa.

Observa-se que, no final do plantão, a variação de "estar com sede", após análise estatística, também demonstrou diferença significativa (Kruskall-Wallis $\mathrm{p}=£ 0,05$ ). O "estar com sede" foi mais intenso no grupo da UTI (25,81\%), seguida pelo grupo do PS (19,23\%). Predominou no grupo do CC o "não estar com sede", totalizando $58,33 \%$ das respostas da unidade. Sugere-se que tal fato é devido à baixa temperatura do local $\left(20^{\circ} \mathrm{C}\right)$.

O cansaço foi uma variável de intensidade forte e marcante ao final do plantão em todas as unidades. No PS e na UTI, a maioria dos profissionais assinalou a resposta "forte" para cansaço, embora no PS 19,23\% dos enfermei-
Estados emocionais de enfermeiros no desempenho profissional em unidades críticas 
Milva Maria F. De Martino Maira Deguer Misko ros mencionaram não se sentirem cansados ao término do plantão. Alguns profissionais já chegavam cansados às suas unidades, alguns por terem mais de um emprego ou por fazerem horas extra e ficarem no hospital por dois turnos consecutivos ou ainda por deixarem as folgas acumularem e trabalharem diversos dias sem descanso. Essas, podem ser as razões do cansaço já no início do período.

As necessidades físicas específicas ou definidas como "cansaço", "sono" e "fome", foram relativamente constantes no grupo estudado, aparecendo com intensidade Forte sobretudo no término do plantão. Com relação à variável sono este, esteve presente na equipe do noturno, no final do plantão. Dados semelhantes foram encontrados ao se estudar um grupo de enfermeiras do turno noturno ${ }^{(9)}$.

Os estados emocionais referidos representam necessidades físicas do organismo humano, que poderiam estar relacionadas a um conjunto de outras variáveis (internas e externas) e que independeriam do trabalho em turno. A fome, por exemplo, ocorreria geralmente no final dos plantões, coincidindo com os horários de refeição (almoço, jantar). O sono foi evidente nos sujeitos do turno noturno, sugerindo uma relação com a privação causada por horários noturnos de trabalho ${ }^{(9)}$.

Em relação ao sono, no início do plantão, este foi de intensidade "forte", sobretudo no turno da manhã, o que pode ser explicitado pelo fato de que as pessoas ainda estavam no início do período do dia e não totalmente despertas. Já no final do plantão, o sono foi característica "forte” para 70, 91\% dos indivíduos. Segundo as respostas, o turno da tarde foi o que se apresentou com a maioria das locuções "sem nenhuma intensidade" para esta variável, o que sugere que os enfermeiros dormem o período de sono noturno de acordo com suas necessidades fisiológicas.

No início do plantão matutino as respostas para a locução "estou cansado", mostraram uma incidência maior quando comparados com os dados dos inícios dos plantões nos diferentes turnos.

Por outro lado, no final dos plantões noturno e vespertino, ficou demonstrado que tal locução também obteve percentagens maiores do que a apresentada no período matutino. Supõe-se que isto seja devido ao fato do período noturno ser de 12 horas de trabalho.
Com relação à locução "sinto-me interessado", a intensidade desta, nos sujeitos, também se mostrou "forte" no início dos plantões, independente dos turnos em que se encontravam os enfermeiros. Sugere-se que tal fato seja atribuído ao desgaste físico e mental do profissional no final do plantão.

A variável "sentir uma necessidade" foi mais intensa no período vespertino, tanto no início como ao final do plantão, tendo sido mais marcante no início. Foi menos observada, com resposta Nenhuma Intensidade, para o período da manhã, tanto no início como no final do plantão.

As respostas para a locução "estou cheio", no início do plantão, totalizou $26,32 \%$ de respostas fortes para o turno da manhã, caracterizando este turno como um dos que apresentavam o sentimento mais exacerbado no início do plantão. Já ao final do turno, foram observadas respostas mais intensas no turno noturno, fato que pode ser devido à jornada de 12 horas de trabalho.

Utilizando o teste de Kruskal-Wallis $(p=£ 0,05)$, observou-se que, quando se compara o valor de intensidade nos diferentes turnos, este foi significativo para as variáveis "sinto ciúme de alguém", "estou gostando de alguém" e "estou refletindo".

Como a locução "reflexão" foi mais fortemente marcada no final do plantão nos turnos da manhã e da tarde, o turno noturno obteve sentimento com intensidade Fraca ou com Nenhuma Intensidade, sugerindo a dificuldade de raciocínio ou diminuição para quem trabalha no turno noturno.

\section{CONCLUSÃO}

O presente estudo permitiu constatar que o perfil emocional dos enfermeiros sofre alterações no decorrer do plantão, o que pode ser creditado ao desgaste e ao estresse próprios da atividade de prestar assistência, sobretudo naquelas unidades, onde há exigência de alto nível de habilidades, necessidade de respostas imediatas em emergências.

Sentimentos negativos como "estou com medo", "acabo de levar um susto", "tenho pena de alguém", "estou com nojo", "sintome culpado", "faço pouco caso de alguém", "estou devendo cuidado", foi constante em todos os grupos estudados com respostas de intensidade "fraca" ou "sem intensidade". 
Estas locuções com baixa ocorrência se caracterizam, em geral, por relatos verbais de valor hedônico negativo.

Verificou-se que sentimentos relacionados a "sentir saudade de alguém", "sentir uma necessidade", "sentir uma obrigação", "estar com esperança", apareceram com respostas de intensidade "forte" ao início e ao final do plantão e foram comuns para as pessoas das três unidades.

Observou-se que algumas locuções apareceram com respostas de maior intensidade no início e no final do plantão, indicando efeitos específicos dos plantões. Assim, no início da jornada de trabalho,as locuções "sinto-me interessado", "sinto-me calmo", "estou refletindo" aparecem com intensidade forte, sofrendo alterações no término do período. No final do plantão, locuções como "estou cheio" e "sinto um alívio" mostraram -se com respostas de intensidade forte, sobretudo nos enfermeiros das unidades UTI e PS.
O cansaço das enfermeiras também foi uma variável predominante nas unidades em estudo, sobretudo no CC e no período noturno.

Com relação ao sono, as pessoas do turno da tarde apresentaram locuções de intensidade "nada" para a variável, o que sugere que as enfermeiras dormem o período de sono noturno de acordo com suas necessidades fisiológicas. Enquanto que para as respostas dos enfermeiros da noite, sobretudo ao final do plantão, foram de intensidade Forte, o que sugere privação de sono por parte destes profissionais.

Verificou-se que ocorreram mudanças nas locuções "estou cansado"," estou cheio", "sinto um alívio", "estou com sono", de acordo com as especificidades de cada turno.

Sugere-se a importância da orientação sobre estado emocional destes profissionais, tanto para administrar a assistência aos pacientes como para si próprios, conforme os achados na literatura.

\section{REFERÊNCIAS}

(1) Engelmann A. Os Estados subjetivos:uma tentativa de classificação de seus relatos verbais. São Paulo: Ática ;1978.

(2) Bueno JL, De Martino MMF, Figueiredo TH. Present mood states in Brazilian night nurses. Psychol Rep 2003; 93:353-357

(3) Engelmann A. LEP- Uma lista de origem brasileira, para medir a presença de estados de ânimo no momento em que está sendo respondida. Ciência Cultura 1986; 38(1): 121-46.

(4) Pafaro RC. Estudo do estresse do enfermeiro com dupla jornada de trabalho em um hospital de oncologia pediátrica de Campinas. [Dissertação] Campinas (SP):Faculdade de Ciências Médicas da UNICAMP; 2002.

(5) Pitta A. Saúde mental e trabalho: a saúde de quem trabalha em saúde. J bras psiq 1994; 41(1):43-50.

(6) Miranda AF. Estresse ocupacional: inimigo invisível do enfermeiro? [Dissertação] Ribeirão Preto(SP):Escola de Enfermagem de Ribeirão Preto/USP; 1998.

(7) Rodrigues E, Lins C. Enfermagem no nordeste: momento e tendências. Enferm científica 1990; $1: 28-31$.

(8) De Martino MMF. Alterações circadiana dos sinais fisiológicos e de estados emocionais e mudanças de atitudes em enfermeiros, em função do trabalho em turno noturno.[Dissertação] Ribeirão Preto(SP):Faculdade de Filosofia Ciências e Letras da USP; 1989.
(9) Shimisuh E. Sofrimento e prazer no trabalho vivenciado por enfermeiras que trabalham em Unidade de Terapia Intensiva em um Hospital-Escola.[Dissertação] São Paulo(SP):Escola de Enfermagem da USP; 1996

(10) Menzies IO. Funcionamento das organizações como sistemas sociais de defesa contra ansiedade. $2^{\mathrm{a}}$ ed. São Paulo: FGV; 1970 .

(11) Chaves EC. Stress e trabalho do enfermeiro: a influência de características individuais no ajustamento e tolerância ao trabalho noturno. [Tese] São Paulo (SP): Instituto de Psicologia da USP;1994.

(12) Takahashi EIU. As fontes de estresse emocional à criança grave. Rev Esc Enferm USP 1985; 19(1):5-20.

(13) Waldow VR. Cuidar /cuidado: o domínio unificador da enfermagem. In: Waldow VR, Lopes MJM, Meyer DE. Maneiras de cuidar-maneiras de ensinar. Porto Alegre: Artes Médicas; 1995. p. 7-30.

(14) Fischer FM. Trabalho em turnos e relação com saúde-doença. In: Mendes R. Patologia do trabalho. São Paulo: Atheneu; 1996. p. $545-72$.

(15) Nowlis V. Research with the Mood Adjective Check List. In: Tomkins SS, Izard C editors. Affect, Cognition and Personality. Springer; 1965.
Estados emocionais de enfermeiros no desempenho profissional em unidades críticas 